\title{
The Complete Structure of Maleic Anhydride by DRM Microwave Spectroscopy
}

\author{
Otto L. Stiefvater \\ School of Physical and Molecular Sciences, University College of North Wales, Bangor, Gwynedd,
} LL57 2UW, U.K.

Z. Naturforsch. 33 a, 1480-1489 [1978]; received October 18, 1977

\begin{abstract}
Double resonance modulation (DRM) microwave spectroscopy has been used for the study of rotational spectra of normal and 3,4- $\mathrm{d}_{2}$ maleic anhydride, and for the investigation of the isotopic species spectra due naturally occurring ${ }^{13} \mathrm{C}$ - and ${ }^{18} \mathrm{O}$-species of the aforementioned two parent forms. From the experimental data the complete structures of the normal and the 3,4- $\mathrm{d}_{2}$ species were deduced independently to yield the following, averaged bond lengths (in $\AA$ ) and angles (in degrees) for this planar, $\mathrm{C}_{2 \mathrm{v}}$-symmetrical molecule:

$$
\begin{array}{ll}
\mathrm{C}-\mathrm{O}=1.3876 & \mathrm{C}-\mathrm{O}-\mathrm{C}=108.06 \\
\mathrm{C}=\mathrm{O}=1.1962 & \mathrm{O}-\mathrm{C}-\mathrm{C}=108.07 \\
\mathrm{C}-\mathrm{C}=1.4849 & \mathrm{C}-\mathrm{C}=\mathrm{C}=107.90 \\
\mathrm{C}=\mathrm{C}=1.3331 & \mathrm{O}-\mathrm{C}=\mathrm{O}=122.32 \\
\mathrm{C}-\mathrm{H}=1.0791 & \mathrm{C}=\mathrm{C}-\mathrm{H}=129.99
\end{array}
$$

The compatibility of these averaged parameters with individual values obtained for the normal and the $3,4-\mathrm{d}_{2}$ species is better than $0.0004 \AA$ and $0.01^{\circ}$ for distances and angles, respectively.

The internal consistency of the $r_{\mathrm{S}}$ parameters is discussed, and the vibrational contributions to the change in the moments of inertia under isotopic substitution of carbon and oxygen atoms near a principal axis are deduced.

The present structure data are compared with previous results by diffraction methods, and the bond lengths in maleic anhydride are discussed in relation to those in chemically similar substances.
\end{abstract}

\section{Introduction}

In comparison with the efforts required during the first three decades of rotational spectroscopy, developments in microwave-microwave double resonance modulation (DRM) techniques [1, 2] during the past few years have made the determination of accurate molecular structures by the isotopic substitution method [3] both inexpensive and straightforward. Due to the improved sensitivity which can be achieved with DRM spectrometers [2a], the need for the expensive, isotopically samples has been largely eliminated [ $4 \mathrm{~b}, \mathrm{c}, \mathrm{d}, \mathrm{f}, \mathrm{g}]$, while the molecular selectivity inherent in the DRM method $[2 \mathrm{a}, \mathrm{b}]$ has been shown [4a, c, e] to facilitate considerably the identification of the individual rotation spectra associated with excited vibration states $[2 \mathrm{c}]$ and the naturally occurring isotopic species of a given compound. As a result, the structure of many an important substance can now be determined with relative ease, as illustrated with the present study of maleic anhydride.

Reprint requests to Dr. O. L. Stiefvater, School of Physical and Molecular Sciences, University College of North Wales, Bangor, Gwynedd LL57 2UW, United Kingdom.
In addition to the general hope that accurate knowledge of the bond lengths and angles in maleic anhydride will, ultimately, help to advance the understanding of the chemical properties of this compound, there were a number of specific reasons which prompted the present investigation. For instance, in connection with current work on the structures and, particularly, the contribution of vibrational effects to the apparent structure data of the four thiadiazoles [ $4 \mathrm{f}, \mathrm{g}, \mathrm{h}$ ], we were interested in the sign and magnitude of the vibrational contributions $[4 \mathrm{~g}, \mathrm{~h}]$ which falsify the changes in the moments of inertia, and hence limit the validity of the substitution method, when a near-axis oxygen atom is replaced by the $18 \mathrm{O}$ isotope. At the same time, the presence of three oxygen atoms in maleic anhydride seemed to provide another good test case for our previous claim [4c] that the DRM method offers sufficient sensitivity not only for the detection of ${ }^{34} \mathrm{~S}-,{ }^{13} \mathrm{C}$ - and ${ }^{15} \mathrm{~N}$-species in their natural abundances, but also for the observation of the still rarer ${ }^{18} \mathrm{O}$-species (natural abundance: $0.18 \%$ ) of many a compound. Finally, as to date the structure of only one anhydride [5] has been determined spectroscopically, it seemed desirable 
to extend the knowledge of such substances by the study of a cyclic molecule of this type.

The first structural data on maleic anhydride were obtained by Marsh, Ubell and Wilcox [6] who concluded from their X-ray diffraction work that, in the crystalline state, maleic anhydride possesses neither a twofold symmetry axis nor a planar configuration. Hilderbrandt and Peixoto [7], on the other hand, observed that their gas-phase electron diffraction data could be satisfactorily accounted for by the assumption of a planar, $\mathrm{C}_{2 \mathrm{v}}$-symmetrical configuration, - a view which is also prevailant in the infrared studies [8] on this compound. The first microwave investigations of maleic anhydride were conducted by Ramsay and Krisher [9, 10] and, simultaneously, by Williams and Sheridan $[10,11]$. While the latter investigators contributed many valuable measurements [11] on the $Q$-branch of the rotational spectrum, the former determined the dipole moinent $(\mu=3.95 \pm 0.04 \mathrm{D})$ and assigned two excited vibration state spectra. From the variation due to nuclear spin statistics of the intensities of rotational transitions, Ramsay and Krisher also proved unequivocally that, in the vapour phase, maleic anhydride possesses the previously assumed $\mathrm{C}_{2 \mathrm{v}}$-symmetry. Thus, at the outset of the present study, maleic anhydride was known to be a planar, asymmetric rotor $(\varkappa \sim-0.7)$ with a $b$-type rotational spectrum.

\section{Experimental}

\section{a) Instrumental}

Rotational absorptions of maleic anhydride and its isotopic species were observed as DRM signal transitions [2a] without recourse to single resonance techniques. All measurements were made at room temperature and with sample pressures near 30 mtorr. Details of the DRM spectrometer and of our standard mode of operation have been given previously [2a, 12]. Free-running, frequency-swept klystrons (minimum sweep rate: $\sim 1 \mathrm{MHz} / \mathrm{sec}$ ) were used for the signal radiation, and absorptions were observed on the oscilloscope. The frequencymodulated pump radiation was stabilised, and the pump power emitted at the two frequencies was levelled through manual adjustments within the mode of the pump klystron [12]. For each isotopic species of maleic anhydride more than 30 signals could be obtained between 28 and $40 \mathrm{GHz}$ with pump frequencies in $\mathrm{K}$-band $(18-26 \mathrm{GHz})$. OKI klystrons (types $20 \mathrm{~V} 10,22 \mathrm{~V} 10$ and $24 \mathrm{~V} 10 \mathrm{~A}$ ) with output powers between 100 and $200 \mathrm{~mW}$ were found adequate to achieve satisfactory modulation of all signal transitions.

\section{b) Samples}

A commercial sample of maleic anhydride was used without further purification for the measurements on the normal form and its isotopic species involving ${ }^{13} \mathrm{C}$ and ${ }^{18} \mathrm{O}$. The $3,4-\mathrm{d}_{2}$-species was kindly prepared, according to the method of Seltzer [13], by Dr. P. J. Thomas of this department. The percentage enrichment of this species was determined as $\sim 70 \%$ by DRM analysis [2d]. While all isotopic species spectra involving ${ }^{13} \mathrm{C}$ or ${ }^{18} \mathrm{O}$ were first identified in their natural abundances, a small portion of the $3,4-\mathrm{d}_{2}$-species was slightly enriched in ${ }^{18} \mathrm{O}$ to save time during the final stages of the measurements. To this end, 3,4- $\mathrm{d}_{2}$ maleic anhydride was dissolved in $\mathrm{H}_{2}{ }^{18} \mathrm{O}(\sim 20 \%)$ to give maleic acid. After two days the acid was lyophilised and the solid residue was mixed with an equal amount of $\mathrm{P}_{2} \mathrm{O}_{5}$. From this mixture, ${ }^{18} \mathrm{O}$-enriched maleic anhydride $(\sim 5 \%)$ was obtained by vacuum sublimation.

\section{Spectroscopic Results}

\section{a) Normal and 3,4-d $d_{2}$-species}

On the basis of model calculations for the isotopic species it was concluded that the assignments of the corresponding rotational spectra could best be accomplished through the identification of $Q$-branch transitions with $J$-values in the range from $J=16$ to $J=19$. This approach required, of course, reasonably reliable information about the centrifugal distortion constants, since the consistency of least squares fits of transitions with such high $J$-values, - and hence also: the accuracy of the deduced rotational constants and the quality of subsequent repredictions of the spectra - , depends critically on the distortion constants used in the fit. For this reason, we considered it necessary to extend the previous work on the normal species $[9-11]$ before the isotopic species spectra were tackled. The range of $J$-values for $R$-branch transitions was therefore extended from the previous limit $\left(J_{\max }=3\right)$ to $J_{\max }=24$, while $Q$-branch transitions were measured up to $J=21$. The 22 DRM signals observed during 
this stage of the investigation were then combined with 69 transitions from the previous work [11], and rotational and distortion constants were derived by a least squares fit to the Hamiltonian [14]

$$
\begin{aligned}
H=A P_{a}^{2} & +B P_{b}^{2}+C P_{c}^{2} \\
& +(1 / 4)\left(\tau_{a a a a} P_{a}^{4}+\tau_{b b b b} P_{b}^{4}\right. \\
& +\tau_{a a b b} P_{a}^{2} P_{b}^{2} \\
& \left.+\tau_{a b a b} P_{a} P_{b} P_{a} P_{b}\right) .
\end{aligned}
$$

As may be seen from column I of Table 1, the 91 transitions fitted were sufficient to determine all but the distortion constant $\tau_{a a b b}$ to better than $\pm 15 \%$ (three times standard error). To provide a similar reliable basis for the study of the isotopic species spectra associated with the $3,4-\mathrm{d}_{2}$-species as "parent" molecule, 78 DRM signals were measured for this species, including $38 R$-branch transitions with $J_{\max }=25$. From these data, all four distortion constants (column VI of Table 1) could be determined to better than $\pm 15 \%$ by the least squares fit to Equation (1).

\section{b) Assignment of ${ }^{13} \mathrm{C}$ - and ${ }^{18} \mathrm{O}$-species}

As planned (above), all isotopic species spectra were assigned on the basis of the high- $J, Q$-branch transitions mentioned above. For speed and decisiveness, pump transitions with two signal connections were chosen for the "initial" [2d] DRM experiments, the signals being located through double searches $[2 \mathrm{a}]$ in frequency areas preselected in accord with the model calculations. After a sufficient number $(\sim 10)$ of $Q$-branch lines had thus been identified and fitted, precisely predictable

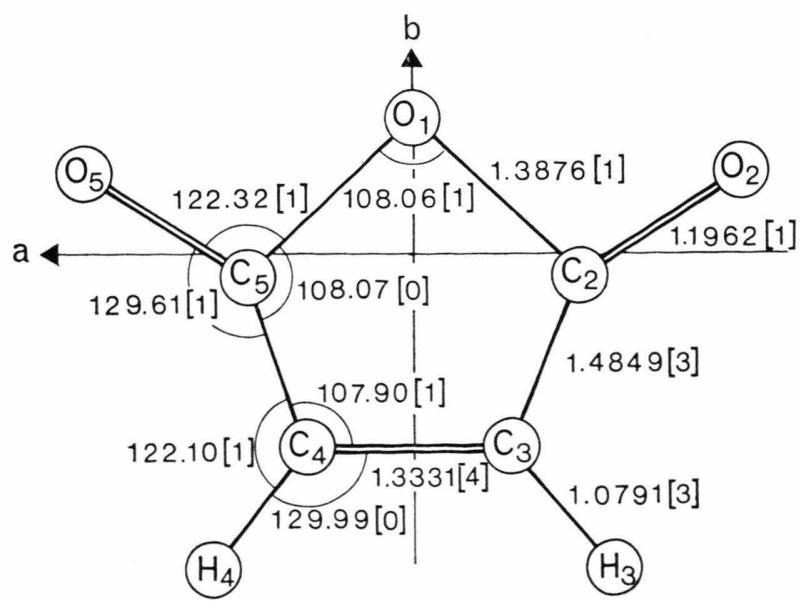

Fig. 1. The structure of maleic anhydride. (See text for significance of square brackets.)
$Q$-branch transitions were used as pump lines for $R$-branch transitions, whose identification completed the assignments.

\section{c) Sequence of isotopic analysis}

As the rotational spectrum of maleic anhydride has been reported to be dense and to contain a number of excited vibration state spectra [9-11], we considered it expedient to evade this spectral complexity by starting the isotopic work with that species whose transitions are furthest removed from the corresponding transitions of the normal species. Accordingly, the spectrum due to ${ }^{13} \mathrm{C}$ in the 3- and 4-position (see Fig. 1 for the numbering of atoms) was identified first, although the uncertainty in the location of these atoms, and hence also in the predicted rotational constants and transition frequencies, were largest for this isotopic species. Knowledge of the relative strength of transitions due to ${ }^{13} \mathrm{C}$ in equivalent positions was then used to help the identification of the ${ }^{13} \mathrm{C}(2 / 5)$ spectrum which occurs close enough to the parent species to be intermingled with the vibrational satellite spectra. The ${ }^{18} \mathrm{O}(2 / 5)$-spectrum with about one fifth of the intensity of ${ }^{13} \mathrm{C}$-spectra was identified next, and the ${ }^{18} \mathrm{O}(1)$-spectrum was identified last. For the ${ }^{13} \mathrm{C}$ - and ${ }^{18} \mathrm{O}$-spectra associated with the 3,4- $\mathrm{d}_{2}$-species as "parent" molecule the same sequence of analysis was adhered to. During all these experiments attention was paid to the intensity of corresponding transitions of different isotopic species, and the results were found in agreement with the $\mathrm{C}_{2 \mathrm{v}}$-symmetry of the molecule, as established in the previous work [9].

\section{d) Derivation of rotational parameters}

Rotational and distortion constants for the isotopic species were derived in essentially the same way as described above for the two "parent" forms. However, as it was not possible for the rare isotopic species to observe many of the weak, high- $J$ $R$-branch transitions necessary for the determination of the distortion constant $\tau_{a a b b}$, this constant was assigned the same value as in the normal and 3,4- $\mathrm{d}_{2}$-species, respectively, when the associated ${ }^{13} \mathrm{C}$ - and ${ }^{18} \mathrm{O}$-spectra were fitted to the Hamiltonian (1).

The spectroscopic parameters of the normal and the isotopic species of maleic anhydride are collected in Table 1, which also contains information on the 
Table 1. Rotational parameters of the parent and isotopic species of Maleic Anhydride.

\begin{tabular}{|c|c|c|c|c|c|c|}
\hline $\begin{array}{l}1 \\
2\end{array}$ & $\begin{array}{l}\text { Spectrum } \\
\text { Isotopic species }\end{array}$ & $\begin{array}{l}\text { I } \\
\text { Parent }\end{array}$ & ${ }_{18}^{\text {II }} \mathrm{O}(1)$ & $\begin{array}{l}\text { III } \\
180(2 / 5)\end{array}$ & $\begin{array}{l}\text { IV } \\
{ }^{13} \mathrm{C}(2 / 5)\end{array}$ & $\begin{array}{l}\mathrm{V} \\
{ }^{13} \mathrm{C}(3 / 4)\end{array}$ \\
\hline $\begin{array}{l}3 \\
4 \\
5\end{array}$ & $\begin{array}{l}\text { Transitions in fit } \\
\text { Range of } J \text {-values } \\
\text { Standard deviation (in } \mathrm{MHz} \text { ) }\end{array}$ & $\begin{array}{l}24 \mathrm{R} \& 67 \mathrm{Q} \\
0-24 \& 4-21 \\
\quad 0.09\end{array}$ & $\begin{array}{l}14 \mathrm{R} \& 15 \mathrm{Q} \\
3-13 \& 5-16 \\
\quad 0.07\end{array}$ & $\begin{array}{l}13 \mathrm{R} \& 23 \mathrm{Q} \\
4-20 \& 5-17 \\
\quad 0.13\end{array}$ & $\begin{array}{l}18 \mathrm{R} \& 20 \mathrm{Q} \\
3-20 \& 5-16 \\
\quad 0.11\end{array}$ & $\begin{array}{l}14 \mathrm{R} \& 24 \mathrm{Q} \\
3-21 \& 5-16 \\
\quad 0.08\end{array}$ \\
\hline $\begin{array}{l}6 \\
7 \\
8\end{array}$ & $\left.\begin{array}{l}A \\
B \\
C\end{array}\right\} \quad$ in $\mathrm{MHz}$ & $\begin{array}{ll}6842.486 & (13)^{\mathrm{b}} \\
2467.614 & (8) \\
1813.627 & (8)\end{array}$ & $\begin{array}{ll}6688.643 & (24) \\
2467.808 & (8) \\
1802.755 & (5)\end{array}$ & $\begin{array}{ll}6790.337 & (44) \\
2354.397 & (11) \\
1748.276 & (8)\end{array}$ & $\begin{array}{ll}6841.501 & (33) \\
2452.607 & (9) \\
1805.442 & (6)\end{array}$ & $\begin{array}{ll}6691.282 & (23) \\
2462.240 & (6) \\
1799.954 & (5)\end{array}$ \\
\hline $\begin{array}{r}9 \\
10 \\
11\end{array}$ & $\left.\begin{array}{l}\tau_{a a a a} \\
\tau_{b b b b} \\
\tau_{a b a b} c\end{array}\right\}$ in $\mathrm{kHz}$ & $\begin{array}{rr}-11.25 & (42) \\
-0.78 & (05) \\
-1.22 & (17)\end{array}$ & $\begin{array}{ll}-12.2 & (36) \\
-0.75 & (15) \\
-0.78 & (30)\end{array}$ & $\begin{array}{ll}-9.3 & (69) \\
-0.75 & (13) \\
-1.24 & (45)\end{array}$ & 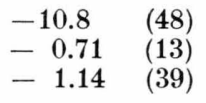 & $\begin{array}{ll}-11.5 & (33) \\
-0.80 & (9) \\
-1.15 & (27)\end{array}$ \\
\hline $\begin{array}{l}12 \\
13 \\
14\end{array}$ & $\left.\begin{array}{l}I_{a} \\
I_{b} \\
I_{c}\end{array}\right\}$ & 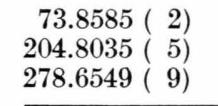 & $\begin{array}{r}75.5573(3) \\
204.7874(7) \\
280.3354(7)\end{array}$ & $\begin{array}{r}74.4258(5) \\
214.6520(10) \\
289.0711(13)\end{array}$ & $\begin{array}{r}73.8692(4) \\
206.0567(7) \\
279.9181(9)\end{array}$ & $\begin{array}{r}75.5275(3) \\
205.2505(4) \\
280.7716(8)\end{array}$ \\
\hline 15 & I.D. $=I_{c}-I_{a}-I_{b}$ & $-0.0072(11)$ & $-0.0094(10)$ & $-0.0067(18)$ & $-0.0077(12)$ & $-0.0064(10)$ \\
\hline
\end{tabular}

\begin{tabular}{|c|c|c|c|c|c|c|}
\hline$\left\{\begin{array}{l}1 \\
2\end{array}\right.$ & $\begin{array}{l}\text { Spectrum } \\
\text { Isotopic species }\end{array}$ & $\begin{array}{l}\mathrm{VI} \\
\mathrm{D}(3 / 4)\end{array}$ & $\begin{array}{l}\text { VII } \\
\mathrm{D}(3 / 4)-18 \mathrm{O}(1)\end{array}$ & $\begin{array}{l}\text { VIII } \\
\mathrm{D}(3 / 4)-18 \mathrm{O}(2 / 5)\end{array}$ & $\begin{array}{l}\text { IX } \\
\mathrm{D}(3 / 4)-13 \mathrm{C}(2 / 5)\end{array}$ & $\begin{array}{l}\mathrm{X} \\
\mathrm{D}(3 / 4)-13 \mathrm{C}(3 / 4)\end{array}$ \\
\hline $\begin{array}{l}3 \\
4 \\
5\end{array}$ & $\begin{array}{l}\text { Transitions in fit } \\
\text { Range of } J \text {-values } \\
\text { Standard deviation (in } \mathrm{MHz} \text { ) }\end{array}$ & $\begin{array}{l}38 \mathrm{R} \& 40 \mathrm{Q} \\
2-25 \& 4-24 \\
0.06\end{array}$ & $\begin{array}{l}24 \mathrm{R} \& 19 \mathrm{Q} \\
3-25 \& 7-18 \\
\quad 0.09\end{array}$ & $\begin{array}{l}22 \mathrm{R} \& 25 \mathrm{Q} \\
4-25 \& 5-19 \\
\quad 0.07\end{array}$ & $\begin{array}{l}16 \mathrm{R} \& 24 \mathrm{Q} \\
4-17 \& 5-18 \\
0.09\end{array}$ & $\begin{array}{l}13 \mathrm{R} \& 18 \mathrm{Q} \\
3-16 \& 8-18 \\
\quad 0.09\end{array}$ \\
\hline $\begin{array}{l}6 \\
7 \\
8\end{array}$ & $\left.\begin{array}{l}A \\
B \\
C\end{array}\right\} \quad$ in $\mathrm{MHz}$ & $\begin{array}{ll}6106.159 & (7) \\
2423.551 & (3) \\
1734.998 & (3)\end{array}$ & $\begin{array}{l}5971.996 \\
2423.742 \\
1724.104\end{array}$ & $\begin{array}{l}6058.195 \\
2314.121 \\
1674.540\end{array}$ & $\begin{array}{rr}6104.567 & (25) \\
2409.078 & (8) \\
1727.440 & (5)\end{array}$ & $\begin{array}{ll}5993.203 & (28) \\
2418.373 & (7) \\
1723.126 & (5)\end{array}$ \\
\hline $\begin{array}{r}9 \\
10 \\
11\end{array}$ & $\left.\begin{array}{l}\tau_{a a a a} \\
\tau_{b b b b} \\
\tau_{a b a b} \mathrm{c}\end{array}\right\}$ in $\mathrm{kHz}$ & $\begin{array}{ll}-8.69 & (12) \\
-0.71 & (2) \\
-1.09 & (6)\end{array}$ & $\begin{array}{ll}-7.6 & (13) \\
-0.69 & (7) \\
-1.04 & (16)\end{array}$ & $\begin{array}{lr}-8.9 & (14) \\
-0.66 & (5) \\
-1.01 & (12)\end{array}$ & $\begin{array}{ll}-10.1 & (30) \\
-0.77 & (9) \\
-0.96 & (27)\end{array}$ & $\begin{array}{ll}-8.3 & (30) \\
-0.72 & (11) \\
-0.98 & (27)\end{array}$ \\
\hline $\begin{array}{l}12 \\
13 \\
14\end{array}$ & $\left.\begin{array}{l}I_{a} \\
I_{b} \\
I_{c}\end{array}\right\}$ & $\begin{array}{r}82.7650(1) \\
208.5271(2) \\
291.2834(5)\end{array}$ & $\begin{array}{r}84.6243(2) \\
208.5106(5) \\
293.1239(7)\end{array}$ & $\begin{array}{r}83.4202(2) \\
218.3879(5) \\
301.7999(6)\end{array}$ & $\begin{array}{r}82.7865(3) \\
209.7798(7) \\
292.5578(9)\end{array}$ & $\begin{array}{r}84.3249(4) \\
208.9736(7) \\
293.2902(9)\end{array}$ \\
\hline 15 & I.D. $=I_{c}-I_{a}-I_{b}$ & $-0.0086(6)$ & $-0.0110(9)$ & $-0.0082(8)$ & $-0.0086(11)$ & $-0.0082(12)$ \\
\hline
\end{tabular}

a Based on 69 transitions from ref. 11 and 22 DRM signals.

b Uncertainties are three times the standard error, and given in units of the last digit quoted.

c The distortion constant $\tau_{a a b b}\left(0.710 \pm 0.35 \mathrm{kHz}\right.$ and $0.61 \pm 0.11 \mathrm{kHz}$ for the normal and the $3,4-\mathrm{d}_{2}$-species, respectively) was held fixed for the heavy isotopic forms.

d Conversion factor: $5.05376 \times 10^{5} \mathrm{MHz} \mu \AA^{2}$.

number of $R$ - and $Q$-branch transitions observed for each isotopic form. For reasons given previously [2a], pump frequencies were not included in the least squares fits. Listings of all signal transitions have been deposited with the "Zentrum für Struktur-Dokumentation" of the University of Ulm (West Germany).

\section{Structure Calculation}

The data of Table 1 represent two complete sets of isotopic species: From the moments in columns I-VI the atomic coordinates in maleic anhydride can be calculated with respect to the principal intertial axes of the normal species, while from the moments in columns $\mathrm{I}$ and $\mathrm{VI}-\mathrm{X}$ coordinates with respect to the axes of the $3,4-\mathrm{d}_{2}$-species can be derived. As the two coordinate systems differ merely through the translation of the origin along the $b$-axis, the two independently calculable values for each $a$-coordinate should coincide, and the values of corresponding $b$-coordinates should differ by a constant amount, equal to the shift of the centre of gravity under substitution of the two hydrogen atoms by deuterium. On account of these 
Table 2. Structure calculations for Maleic Anhydride.

\begin{tabular}{|c|c|c|c|c|c|c|c|c|}
\hline & \multirow[b]{2}{*}{ Coordinates } & \multicolumn{2}{|c|}{ Normal Species } & \multicolumn{3}{|l|}{$3,4-d_{2}-$ Species } & \multicolumn{2}{|c|}{ Combined data ${ }^{a}$} \\
\hline & & $|a|$ & $b$ & $|a|$ & $b$ & $b_{\mathrm{i}}^{\mathrm{D}_{2}}-b_{\mathrm{i}}^{\mathrm{H}_{2}}$ & $|a|$ & $b$ \\
\hline 1 & $\mathrm{O}(1)$ & - & $+0.92971[30]^{\mathrm{b}}$ & - & $0.97247[31]^{\mathrm{b}}$ & 0.04276 & - & $-0.92970[1]^{\mathrm{c}}$ \\
\hline 2 & $\mathrm{O}(2 / 5)$ & $2.23442[3]$ & $+0.55732[17]$ & $2.23439[3]$ & $0.59976[13]$ & 0.04244 & $2.23440[2]$ & $0.55716[16]$ \\
\hline 3 & $\mathrm{C}(2 / 5)$ & $1.12314[17]$ & $\begin{array}{l}(0.10301[190])^{\mathrm{d}} \\
0.11464 \mathrm{e}^{\mathrm{a}}\end{array}$ & $1.12290[2]$ & $\begin{array}{l}(0.14820[16])^{\mathrm{d}} \\
0.15735 \mathrm{e}^{\mathrm{e}}\end{array}$ & $\begin{array}{c}(0.04519) \\
0.04271\end{array}$ & $1.12302[12]$ & $\begin{array}{l}(0.11461[3])^{\mathrm{e}} \\
0.11463 \mathrm{e}^{-}\end{array}$ \\
\hline 4 & $\mathrm{C}(3 / 4)$ & $0.66675[37]$ & $-1.29863[20]$ & $0.66636[21]$ & $-1.25539[11]$ & 0.04324 & $0.66655[20]$ & $-1.29840[23]$ \\
\hline 5 & $\mathrm{H}(3 / 4)$ & $1.36007[14]$ & $-2.10508[9]$ & $1.36007[14]$ & $\begin{array}{r}-2.08231[9] \\
\text { Average: }\end{array}$ & $\begin{array}{l}0.04277 \\
0.04278\end{array}$ & $1.36007[-]$ & $-2.12508[-]$ \\
\hline
\end{tabular}

\begin{tabular}{|c|c|c|c|c|}
\hline \multicolumn{5}{|c|}{ Bond lengths } \\
\hline 6 & $\mathrm{O}(1)-\mathrm{C}(2 / 5)$ & 1.38773 & 1.38756 & $1.38763[10]$ \\
\hline 7 & $\mathrm{C}(2 / 5)-\mathrm{C}(3 / 4)$ & 1.48513 & 1.48468 & $1.48493[25]$ \\
\hline 8 & $\mathrm{C}(3)-\mathrm{C}(4)$ & 1.33350 & 1.33272 & $1.33310[40]$ \\
\hline 9 & $\mathrm{C}(2 / 5)-\mathrm{O}(2 / 5)$ & 1.19620 & 1.19630 & $1.19624[6]$ \\
\hline \multirow[t]{2}{*}{10} & $\mathrm{C}(3 / 4)-\mathrm{H}(3 / 4)$ & 1.07875 & 1.07936 & $1.07906[30]$ \\
\hline & \multicolumn{4}{|l|}{ Bond angles } \\
\hline 11 & $\mathrm{C}(2) \mathrm{O}(1) \mathrm{C}(5)$ & 108.06 & 108.05 & $108.06[1]$ \\
\hline 12 & $\mathrm{O}(1) \mathrm{C}(2 / 5) \mathrm{C}(3 / 4)$ & 108.07 & 108.07 & $108.07[0]$ \\
\hline 13 & $\mathrm{C}(2 / 5) \mathrm{C}(3) \mathrm{C}(4)$ & 107.90 & 107.91 & $107.90[1]$ \\
\hline \multirow[t]{2}{*}{14} & $\mathrm{O}(1) \mathrm{C}(2 / 5) \mathrm{O}(2 / 5)$ & 122.31 & 122.32 & $122.32[1]$ \\
\hline & $\mathrm{C}(3 / 4) \mathrm{C}(2 / 5) \mathrm{O}(2 / 5)$ & 129.62 & 129.61 & $129.61[1]$ \\
\hline \multirow[t]{3}{*}{15} & $\mathrm{C}(2 / 5) \mathrm{C}(3 / 4) \mathrm{H}(3 / 4)$ & 122.11 & 122.10 & $122.10[1]$ \\
\hline & $\mathrm{C}(3) \mathrm{C}(4) \mathrm{H}(3 / 4)$ & 129.99 & 129.99 & $129.99[0]$ \\
\hline & \multicolumn{4}{|c|}{ Effective and calculated moments } \\
\hline 16 & $I_{a}^{\text {subst }}$ & 73.6542 & 82.5182 & 73.6338 \\
\hline 17 & $I_{a}^{\mathrm{eff}}-I_{a}^{\mathrm{subst}}$ & $0.2044(0.28 \%)$ & $0.2468(0.30 \%)$ & $0.2248(0.30 \%)$ \\
\hline 18 & $I_{b}^{\text {subst }}$ & 204.3860 & 208.0791 & 204.3703 \\
\hline 19 & $I_{b}^{\text {ett }}-I_{b}^{\text {subst }}$ & $0.4175(0.20 \%)$ & $0.4480(0.21 \%)$ & $0.4333(0.21 \%)$ \\
\hline
\end{tabular}

a For method of combination, see text.

b The uncertainties quoted here reflect the compatibility of coordinates when calculated from the three pairs of $\Delta I$-values.

c These quantities reflect the compatibility between data derived in the normal and the 3,4- $\mathrm{d}_{2}$ reference frame.

d Substitution value.

e Value derived from first moment condition. 
two criteria the structure determination in two reference frames is seen to provide an internal check on the reliability of the overall results.

While the previous work [9] and the relative intensity measurements of the present study leave no doubt about the $\mathrm{C}_{2 \mathrm{v}}$ symmetry of maleic anhydride, the quasi-constancy of the inertia defect under isotopic substitutions (row 15 of Table 1) provides conclusive evidence for the planarity of this compound in the vapour phase. Accordingly, we have used Kraitchman's equations [3a] for planar molecules to evaluate the atomic coordinates. However, as these equations are based on the idealising assumption that the change in the inertia defect under substitution is exactly zero, we have calculated the $a$ - and $b$-coordinates of every atom not only from the inertial differences $\Delta I_{a}$ and $\Delta I_{b}$, but also from the pairs $\Delta I_{a}, \Delta I_{c}$ and $\Delta I_{b}, \Delta I_{c}$. In this method of calculation the small changes in the inertial defect re-appear as variations in the atomic coordinates. The three values obtained by this procedure for every coordinates were then averaged, and the largest deviation of an individual coordinate value from the average was taken as a measure for the reliability of the average value. In Table 2 these quantities are given in square brackets.

For the oxygen atom on the symmetry axis the outlined procedure could not be applied without modification because the moments $I_{b}$ of both ${ }^{18} \mathrm{O}(1)$-species are smaller than those of their respective "parent" molecules (compare row 13, columns I, II and VI, VII of Table 1). The $b$ coordinates of this atom were therefore calculated once from the observed changes in $I_{a}$ alone, and then from the combined changes in $I_{b}$ and $I_{c}$, that is : from the quantity $\Delta I_{a}{ }^{*}=\Delta I_{c}-\Delta I_{b}$. In analogy with the view adopted for the other coordinates, the deviation of the two values obtained from $\Delta I_{a}$ and $\Delta I_{a} *$ from their average was again taken as the "uncertainty" in this coordinate. The $b$ coordinate of the two simultaneously substituted hydrogen atoms $\mathrm{H}(3 / 4)$ was calculated in the same manner, while the $a$-coordinate was derived from the relation $\Delta I_{b}^{\mathrm{H}_{2} / \mathrm{D}_{2}}=2\left(m_{\mathrm{D}}-m_{\mathrm{H}}\right) a_{\mathrm{H}}{ }^{2}$. As for the $\mathrm{O}(1)$-atom, the observed $\Delta I_{b}$-value was used in this equation as well as $\Delta I_{b} *=\Delta I_{c}-\Delta I_{a}$, and the two results were averaged.

The two carbon atoms $\mathrm{C}(2 / 5)$, finally, are seen from Fig. 1 to lie very close to the $a$-axis, and their substitution coordinates (given in brackets in row 3 of Table 2) must therefore be suspected of being falsified by vibrational contributions to the small $\Delta I_{a}$-values. Strong evidence for this is found by a comparison of the corresponding coordinate values in the normal and the $3,4-\mathrm{d}_{2}$ reference frame: whereas the differences between all other pairs of $b$-coordinates deviate by less than $0.0005 \AA$ from the expected shift of the centre of gravity, the two values for the $b$-coordinate of $\mathrm{C}(2 / 5)$ lead to a five times larger discrepancy $(0.0024 \AA)$. For this reason, the $b$-coordinates of $\mathrm{C}(2 / 5)$ were determined from the first moment conditions $\sum m_{i} b_{i}=0$ after all other atoms had been located. In this context it should be mentioned that, while the uncertainties remaining after the use of the centre-of-gravity condition are normally small when a heavy, nearaxis atom is located from the known positions of lighter atoms, the reverse situation is encountered with the $b_{\mathrm{C}(2 / 5)}$-values in the present case because the combined uncertainties in the $b$-coordinates of the three oxygen atoms are magnified by a factor 2 $(=3 \times 16 / 2 \times 12)$.

The coordinate sets derived independently in the principal axis systems of the normal and the $3,4-\mathrm{d}_{2}$-species of maleic anhydride are given in rows $1-5$ of Table 2 , and the deduced bond lengths and angles are listed in the lower half of this table. The differences between corresponding $b$-coordinates in the two reference frames are given in the fifth data column of this table. Inspection of these differences, $b_{i}^{\mathrm{D}_{2}}-b_{i}^{\mathrm{H}_{2}}$, shows good agreement for the two coordinate values for $b_{\mathrm{C}(2 / 5)}$, as determined from the first moment condition, with the value expected for the shift of the centre of gravity when calculated from the position of the hydrogen atoms $\mathrm{H}(3 / 4) \quad\left(b_{\mathrm{S}}=0.04277 \AA\right)$. The largest discrepancy between $b$-coordinates in the two reference frames is seen to occur for the $\mathrm{C}(3 / 4)$ atoms, which also differ by the largest amount in their $a$-coordinates.

To derive an optimal structure encompassing all isotopic data for maleic anhydride, the coordinate values deduced independently in the normal and the 3,4-d $\mathrm{d}_{2}$ reference frame were finally combined in the following way: For the $a$-coordinates which in the ideal case, should be the same in the two coordinate systems, we have simply taken the averages between corresponding coordinates as the "best" values. For the $b$-coordinates, on the other hand, the values obtained in the $3,4-\mathrm{d}_{2}$ frame were first transformed to the axis system of the normal 
species through subtraction of the average shift of the centre of gravity, as determined from the differences between corresponding $b$-coordinates in the two reference frames, and these transformed $b$-coordinates were then averaged with their counterparts determined in the normal axis system directly. In all cases, the difference between individual values and their averages was taken as a measure for the reliability of the "best" coordinates. Their values are given in square brackets in the columns headed "combined data" in Table 2. Bond distances and angles deduced from the "combined" coordinates are given in rows $6-15$, with quantities in square brackets having the same significance as before.

\section{Discussion}

\section{a) Experimental method}

The abundance of isotopic data in this and previous structure studies [4] by DRM microwave spectroscopy clearly confirms our initial optimism $[4 \mathrm{~b}, \mathrm{c}]$ concerning the power and economic advantages of this experimental approach. A re-evaluation of its merits is therefore superfluous. With respect to the likely objection that the large dipole moment of maleic anhydride $(\mu=3.95 \mathrm{D})$ essentially invalidates conclusions about the sensitivity of the DRM method in the present case, the following point should perhaps be added: While a large molecular dipole moment clearly reduces the amount of pump power necessary for satisfactory modulation [2a] of a DRM signal transition, the intensity of the latter depends, among other factors, on the population of the levels involved, and hence on the vibrational partition function. Thus, due to the presence of several low frequency modes with sizeable populations at room temperature, the intensity of ground state transitions of the parent species of maleic anhydride was found considerably smaller than in the case of isoxazole [4c] $\left(\mu_{a} \cong\right.$ $\left.\mu_{b} \cong 2 \mathrm{D}\right)$ or oxazole $[15]\left(\mu_{b} \cong 0.9 \mathrm{D}\right)$, and not too much larger than the intensity of the $b$-type transitions of $i s o$-butyraldehyde [16] $\left(\mu_{b} \cong 0.8 \mathrm{D}\right)$ at $-78^{\circ} \mathrm{C}$. However, in all these cases transitions of the $18 \mathrm{O}$-species have been detected in natural abundance, and we are confident therefore that the DRM technique will allow this rare isotopic species to be identified in its natural abundance in a great many other compounds.

\section{b) Internal consistency of $r_{\mathrm{S}}$ parameters, vibrational contributions}

From the last column of Table 2, the $r_{\mathrm{S}}$ param. eters deduced in the principal axis systems of the normal and the 3,4- $\mathrm{d}_{2}$ species are seen to be highly compatible so that by Costain's criterion [3c] (independence of the $r_{\mathrm{S}}$ parameters from the isotopic species used) the present results can be classified as accurate. The largest discrepancy in the internuclear distances occurs for the bond length $\mathrm{C}(3)=\mathrm{C}(4)$ which, when determined in the $3,4-\mathrm{d}_{2}$ frame, turns out $0.0008 \AA$ shorter than in the normal species. While we were at first inclined to attribute this to experimental inaccuracy, we have since obtained an exactly analogous result in the case of 1,2,5-thiadiazole $[4 \mathrm{~h}]$, and we suspect therefore that the apparent shortening of the $\mathrm{C}(3)=\mathrm{C}(4)$ bond upon deuteration of the attached hydrogens represents most probably the same "diatomic effect" [3b, c] as that observed by Schwendeman and Kelly [17] in methyl chloride and methyl bromide.

A particularly gratifying aspect of the present study is the good consistency of the values for the shift of the centre of gravity upon deuteration, as determined from the $b$-coordinates of atoms in the two reference frames (Table 2 , column 5 , rows $1-5$ ), and the agreement of these values with the shift of the centre of gravity calculated from the substitution coordinates of the hydrogen atoms directly. Especially the compatibility of the difference between the two $b_{\mathrm{C}(2 / 5)}$-coordinates with the latter value suggests that the error limits quoted for the other heavy atoms are too pessimistic. In consequence, if one is justified in placing as much confidence in the accuracy of the coordinates as their internal consistency seeins to imply, one may, as in the previous case of 1,2,4-thiadiazole [ $4 \mathrm{~g}$ ], evaluate the vibrational contribution to the small $\Delta I_{a}$-value of the $\mathrm{C}(2 / 5)$ atoms in the normal (and $\left.3,4-\mathrm{d}_{2}\right)$ reference frame:

$$
\begin{aligned}
\Delta I_{a}^{\mathrm{vib}}(\mathrm{C}(2 / 5)) & =\Delta I_{a}^{\mathrm{eff}}-\Delta I_{a}^{\text {calc }} \\
& =-0.0023(-0.0028) \mu \AA^{2} .
\end{aligned}
$$

Here, $\Delta I^{\text {eff }}$ is the observed change in the moment under ${ }^{13} \mathrm{C}$ substitution, and $\Delta I^{\text {calc }}$ is the change which would be expected from the "final" coordinate value of the substituted atom. For the oxygen atom on the symmetry axis the vibrational contribution is, of course, obtained from the observed 
$I_{b}$-values directly since $\Delta I_{b}^{\text {calc }}=0$.

$$
\begin{aligned}
\Delta I_{b}^{\mathrm{vib}}(\mathrm{O}(1)) & =\Delta I_{b}^{\mathrm{eff}} \\
& =-0.0161(-0.0164) \mu \AA^{2} .
\end{aligned}
$$

While the first of these values qualitatively agrees with the previous result $[4 \mathrm{~g}]$ for a near-axis carbon atom, the latter contribution is unexpectedly large, implying that extra caution is perhaps advisable in the interpretation of the substitution coordinate of near-axis oxygen atoms. In this context it seems worth mentioning that the addition of $0.0161 \mu \AA^{2}$, as determined above, to the observed (negative) $\Delta I_{b}$-value for the central oxygen atom in formic anhydride [5] would place that atom $0.049 \AA$ from the $b$-axis, a distance which differs by only $0.007 \AA$ from the value deduced by Günthard and collaborators from a complete set of singly substituted species by use of the first moment condition.

\section{c) Molecular structure}

\section{Comparison with diffraction methods}

The strusture of maleic anhydride, as deduced in Section IV, is shown in Fig. 1, and the present results may be compared with those of the earlier work by X-ray [6] and gas-phase electron diffraction (E.D.) [7] techniques with the help of Table 3. Although different physical quantities are determined in the spectroscopic and the diffraction methods, the present data broadly confirm the previous results, though much of this agreement is clearly due to the fact that the uncertainties inherent in the diffraction methods are sufficiently large to encompass the spectroscopic values. An exception to this occurs only with the E.D. value for the bond length $\mathrm{C}(2 / 5)-\mathrm{C}(3 / 4)$ which exceeds the spectroscopic value by $0.015 \AA$, which is three times the quoted uncertainty. The average X-ray value for this bond is by the same amount smaller than the present result. The E.D. value for the $\mathrm{C}(3)=\mathrm{C}(4)$ double bond, in contrast, coincides very closely with the present result, suggesting that the quoted uncertainty of the former $( \pm 0.03 \AA)$ is perhaps too pessimistic.

From the lower half of Table 3 the average values for the ring angles determined by X-ray diffraction are seen to agree slightly better with the present results than those deduced by E.D., and it should perhaps be noted that the variation within the three non-equivalent ring angles is less than $0.2^{\circ}$
Table 3. Comparison of bond distances (in $\AA$ ) and angles (in degrees) in maleic anhydride as derived by $\mathrm{X}$-ray diffraction, electron diffraction and DRM microwave spectro-

\begin{tabular}{|c|c|c|c|}
\hline & $\begin{array}{l}\text { X-ray } \\
\text { Diffraction } \\
\text { (Ref. 6) }\end{array}$ & $\begin{array}{l}\text { Electron } \\
\text { Diffraction } \\
\text { (Ref. 7) }\end{array}$ & $\begin{array}{l}\text { DRM } \\
\text { Microwave } \\
\text { Spectrosc. } \\
\text { (This study) }\end{array}$ \\
\hline \multicolumn{4}{|c|}{ Average } \\
\hline $\begin{array}{l}\mathrm{O}(1)-\mathrm{C}(2)^{\mathrm{a}} \\
\mathrm{O}(1)-\mathrm{C}(5)\end{array}$ & $\left.\begin{array}{l}1.393 \\
1.383\end{array}\right\} 1.388$ & $1.394(11)$ & $1.3876(1)^{\mathrm{b}}$ \\
\hline $\begin{array}{l}\mathrm{C}(2)-\mathrm{C}(3) \\
\mathrm{C}(5)-\mathrm{C}(4)\end{array}$ & $\left.\begin{array}{l}1.467 \\
1.472\end{array}\right\} 1.470$ & $1.500(5)$ & 1.4849 \\
\hline $\mathrm{C}(3)=\mathrm{C}(4)$ & $1.303 \quad 1.303$ & $1.330(30)$ & 1.3331 \\
\hline $\begin{array}{l}\mathrm{C}(2)=\mathrm{O}(2) \\
\mathrm{C}(5)=\mathrm{O}(5)\end{array}$ & $\left.\begin{array}{l}1.184 \\
1.194\end{array}\right\} 1.189$ & $1.195(3)$ & 1.1962 (1) \\
\hline $\begin{array}{l}\mathrm{C}(3)-\mathrm{H}(3) \\
\mathrm{C}(4)-\mathrm{H}(4)\end{array}$ & $\left.\begin{array}{l}1.11 \\
1.05\end{array}\right\} 1.08$ & $1.091(21)$ & 1.0791 \\
\hline $\mathrm{C}(5) \mathrm{O}(1) \mathrm{C}(2)$ & $107.5 \quad 107.5$ & 107.0 & 108.06 \\
\hline $\begin{array}{l}\mathrm{O}(1) \mathrm{C}(2) \mathrm{C}(3) \\
\mathrm{O}(1) \mathrm{C}(5) \mathrm{C}(4)\end{array}$ & $\left.\begin{array}{l}107.8 \\
107.6\end{array}\right\} 107.7$ & $108.8(1.2)$ & $108.07(0)$ \\
\hline $\begin{array}{l}\mathrm{C}(2) \mathrm{C}(3) \mathrm{C}(4) \\
\mathrm{C}(5) \mathrm{C}(4) \mathrm{C}(3)\end{array}$ & $\left.\begin{array}{l}108.3 \\
108.8\end{array}\right\} 108.5$ & $107.7(1.0)$ & 107.90 \\
\hline $\begin{array}{l}\mathrm{O}(1) \mathrm{C}(2) \mathrm{O}(2) \\
\mathrm{O}(1) \mathrm{C}(5) \mathrm{O}(5)\end{array}$ & $\left.\begin{array}{l}121.3 \\
120.1\end{array}\right\} 120.7$ & $121.9(1.2)$ & 122.32 \\
\hline $\begin{array}{l}\mathrm{C}(3) \mathrm{C}(2) \mathrm{O}(2) \\
\mathrm{C}(4) \mathrm{C}(5) \mathrm{O}(5)\end{array}$ & $\left.\begin{array}{l}130.9 \\
132.3\end{array}\right\} 131.6$ & $129.3(2.0)$ & 129.61 (1) \\
\hline $\begin{array}{l}\mathrm{C}(2) \mathrm{C}(3) \mathrm{H}(3) \\
\mathrm{C}(5) \mathrm{C}(4) \mathrm{H}(4)\end{array}$ & $\left.\begin{array}{l}120.0 \\
125.0\end{array}\right\} 122.5$ & 123.4 & 122.10 \\
\hline $\begin{array}{l}\mathrm{C}(4) \mathrm{C}(3) \mathrm{H}(3) \\
\mathrm{C}(3) \mathrm{C}(4) \mathrm{H}(4)\end{array}$ & $\left.\begin{array}{l}131.0 \\
126.0\end{array}\right\} 128.5$ & 128.9 & $129.99(0)$ \\
\hline
\end{tabular}
scopy.

a Numbering of atoms as in Figure 1.

b These quantities reflect the compatibility of individual values with the quoted aberage.

according to the present study, while a variation of up to $1.3^{\circ}$ and $1.8^{\circ}$ is indicated by the X-ray and E.D. studies, respectively.

\section{Comparison of maleic anhydride} with related molecules

A direct comparison of the bond length in the $\mathrm{O}=\mathrm{C}-\mathrm{O}-\mathrm{C}=\mathrm{O}$ group of maleic and formic anhydride is, unfortunately, not possible since the latter molecule exists in the EA conformation with the two carbonyl groups in a trans position (see Ref. [5], Figs. 1 and 2). From Table 4 it is noted, however, that the carbon-oxygen single and double bond values of maleic anhydride both occur in formic anhydride, though in different halves of the molecule, and that the average carbon-oxygen bond lengths in formic anhydride (1.376 $\AA$ and $1.190 \AA$ for single and double bonds, respectively) are both shorter than those of maleic anhydride. 
Table 4. Comparison of bond lengths in maleic anhydride with those of related substances.

\begin{tabular}{|c|c|c|c|c|c|c|}
\hline \multirow[t]{2}{*}{ Molecule } & \multicolumn{4}{|c|}{ Bond distance in $\AA$} & \multirow{2}{*}{\multicolumn{2}{|c|}{$\begin{array}{l}\text { Exptl. Ref. } \\
\text { Method }\end{array}$}} \\
\hline & $\mathrm{C}-\mathrm{O}$ & $\mathrm{C}=\mathrm{O}$ & $\mathrm{C}-\mathrm{C}$ & $\mathrm{C}=\mathrm{C}$ & & \\
\hline $\begin{array}{l}\text { Maleic } \\
\text { Anhydride }\end{array}$ & 1.388 & 1.196 & 1.485 & 1.333 & $\begin{array}{l}\text { M.W. } \\
\text { (DRM) }\end{array}$ & $\begin{array}{l}\text { This } \\
\text { study }\end{array}$ \\
\hline $\begin{array}{l}\text { Formic } \\
\text { Anhydride }\end{array}$ & $\begin{array}{l}1.389 \\
1.364\end{array}$ & $\begin{array}{l}1.184 \\
1.195\end{array}$ & - & - & M.W. & {$[5]$} \\
\hline $\begin{array}{l}\text { Maleic } \\
\text { Acid }\end{array}$ & $1.27 \tilde{5}$ & 1.21 & 1.45 & 1.43 & X-ray & {$[20]$} \\
\hline $\begin{array}{l}\text { Formic } \\
\text { Acid }\end{array}$ & 1.343 & 1.201 & - & - & M.W. & {$[19]$} \\
\hline $\begin{array}{l}\text { Propionic } \\
\text { Acid }\end{array}$ & 1.352 & 1.210 & 1.509 & - & $\begin{array}{l}\text { M.W. } \\
\text { (DRM) }\end{array}$ & {$[4 \mathrm{~b}]$} \\
\hline $\begin{array}{l}\text { Methyl } \\
\text { Formate }\end{array}$ & 1.334 & 1.200 & - & - & M.W. & {$[18]$} \\
\hline Acrolein & - & $\begin{array}{l}1.208 \\
1.219\end{array}$ & $\begin{array}{l}1.478 \\
1.470\end{array}$ & $\begin{array}{l}1.335 \\
1.345\end{array}$ & $\begin{array}{l}\text { E.D. } \\
\text { M.W. }\end{array}$ & $\begin{array}{l}{[22]} \\
{[23]}\end{array}$ \\
\hline $\begin{array}{l}\text { 1,3- } \\
\text { Butadiene }\end{array}$ & - & - & 1.467 & 1.343 & E.D. & {$[24]$} \\
\hline Furan & 1.362 & - & 1.431 & 1.361 & M.W. & {$[21]$} \\
\hline Oxazole & $\begin{array}{l}1.369 \\
1.358\end{array}$ & - & - & 1.353 & $\begin{array}{l}\text { M.W. } \\
\text { (DRM) }\end{array}$ & {$[15]$} \\
\hline Isoxazole & 1.344 & - & 1.452 & 1.356 & $\begin{array}{l}\text { M.W. } \\
\text { (DRM) }\end{array}$ & {$[4 \mathrm{c}]$} \\
\hline Ethylene & - & - & - & 1.334 & E.D. & {$[25]$} \\
\hline
\end{tabular}

The anhydride group may therefore be described as less compact in maleic than in formic anhydride, and this is probably due to the geometric restrictions within the ring system.

Comparison with the carboxylic acids and with methyl formate [18] shows that the $\mathrm{C}-\mathrm{O}$ bond

[1] R. C. Woods III, A. M. Ronn, and E. B. Wilson, Jr., Rev. Sci. Instrum. 37, 927 (1966).

[2] O. L. Stiefvater, a) Z. Naturforsch. 30a, 1742 (1975); b) ibid. 30a, $1756(1975)$; c) and d) to be published (Identification of excited vibrational states and isotopic species, respectively).

[3] a) J. Kraitchman, Amer. J. Phys. 21, 17 (1953); b) C. C. Costain, J. Chem. Phys. 29, 864 (1964); c) idem. Trans. Amer. Crystallogr. Assoc. 2, 157 (1966).

[4] O. L. Stiefvater, a) J. Chem. Phys. 62, 233 (1975); b) ibid. 62, 244 (1975); c) ibid. 63, $2560(1975)$; d) Z. Naturforsch. 30a, 1765 (1975); e) ibid. 31a, 53 (1967); f) Chem. Phys. 13, 73 (1976); g) Z. Naturforsch. 31 a, $1681(1976)$; h) IV. European Microwave Conference, Tübingen 1977 (Paper W4).

[5] S. Vaccani, V. Roos, A. Bauder, and Hs. H. Günthard, Chem. Phys. 19, 51 (1977).

[6] R. E. Marsh, E. Ubell, and H. E. Wilcox, Acta Crystallogr. 15, 35 (1962). length of the anhydride is increased by $\sim 0.05 \AA$ (the somewhat extraneous X-ray value for maleic acid [20] has been ignored here) and it is $\sim 0.03 \AA$ longer than in the five-membered rings furan [21], oxazole [15] and isoxazole [4c]. The $\mathrm{C}=\mathrm{O}$ bond, in contrast, is seen to follow the reverse, though less pronounced trend in decreasing from $\sim 1.21 \AA$ in the acids, methyl formate and acrolein $[22,23]$ to $\sim 1.19 \AA$ in the anhydrides.

Bond lengths in the $\mathrm{O}=\mathrm{C}-\mathrm{C}=\mathrm{C}$ section of maleic anhydride approximately resemble those of acrolein and 1,3-butadiene [24], but corresponding single and double bonds are longer and shorter, respectively, in the anhydride than in the other two conjugated systems and in the quasiaromatic five-membered rings. The $\mathrm{C}=\mathrm{C}$ bond length, in particular, is identical with that of ethylene [25].

From all these observations it may be inferred that the partial multiple bond character in the carboxyl groups of carboxylic acids is reduced upon formation of the anhydrides and, in particular, that the electrons in the single and double bonds of maleic anhydride are highly localized.

\section{Acknowledgements}

I am greatly indebted to Dr. Patsy J. Thomas of the physical-organic group of this department for her expert advice in all chemical matters and, in particular, for carrying out the preparations described in section IIb. I would also like to thank Professor L. C. Krisher for providing me with a detailed account of his previous work on maleic anhydride, and Professor Sheridan for continued interest in this substance.

[7] R. L. Hilderbrandt and E. M. A. Peixoto, J. Mol. Structure 12, 31 (1972).

[8] a) P. Mirone and P. Chiorboli, Spectrochim. Acta 18, 1425 (1962); b) C. Di Lauro. S. Califano, and G Adembri, J. Mol. Structure 2, 173 (1968); c) A. Baranska, D. H. Christensen, F. M. Nicolaisen, O. F. Nielsen, and P. Klaeboe, Acta Chem. Scand. 25, 2364 (1971), and earlier papers quoted in these references.

[9] I. A. Ramsay and L. C. Krisher, (private communication).

[10] I. A. Ramsay, L. C. Krisher, V. Williams, and J. Sheridan, 22nd Symp. Mol. Struct. Spectrosc., Columbus, $\mathrm{OH}(1967)$.

[11] V. Williams, Ph. D. Thesis, Wales 1969.

[12] O. L. Stiefvater, H. Jones, and J. Sheridan, Spectrochim. Acta $26 \mathrm{~A}, 825$ (1970).

[13] S. Seltzer, J. Amer. Chem. Soc. 83, 1861 (1961).

[14] P. Nösberger, A. Bauder, and Hs. H. Günthard, Chem. Phys. 1, 426 (1973). 
[15] A. Kumar, J. Sheridan, and O. L. Stiefvater, (to be published).

[16] O. L. Stiefvater, (to be published).

[17] R. H. Schwendeman and J. D. Kelly, J. Chem. Phys. 42, 1132 (1965).

[18] R. F. Curl, J. Chem. Phys. 30, 1529 (1959).

[19] H. Kwei and R. F. Curl, J. Chem. Phys. 32, 1592 (1960) (see also Table XI of Ref. $4 \mathrm{~b}$ ).

[20] M. Shahat, Acta Crystallogr. 5, 763 (1952).
[21] B. Bak, D. Christensen, W. B. Dixon, L. HansenNygaard, J. R. Andersen, and M. Schottländer, J. Mol. Spectry 9, 124 (1962).

[22] M. Traetteberg, Acta Chem. Scand. 24, 373 (1970).

[23] E. A. Cherniak and C. C. Costain, J. Chem. Phys. 45, 104 (1966).

[24] W. Haugen and M. Traetteberg, Acta Chem. Scand. 20, 1726 (1966).

[25] L. S. Bartell and R. H. Bonham, J. Chem. Phys. 31, 400 (1959). 